\title{
O museu na comunidade e a comunidade no museu: o caso do Museu Histórico de Nova Hartz
}

\section{The museum in the community and the community at the museum: the case of the Historical Museum of Nova Hartz}

Resumo: A participação e o envolvimento da comunidade em ações relacionadas ao patrimônio cultural das cidades e aos museus, valorizando saberes dos moradores, dando a eles protagonismo, permite que se reconheçam como detentores de conhecimentos, o que por sua vez possibilita que aconteça a partilha de saberes nesses espaços. Neste estudo, vamos apresentar algumas ações desenvolvidas pelo Museu Histórico de Nova Hartz (Nova Hartz/ RS), que buscam esse protagonismo, com enfoque especial no patrimônio imaterial do município.

Palavras-chave: museu, patrimônio cultural, Nova Hartz/RS

Abstract: The community's participation and involvement in actions related to the cultural heritage of the cities and museums, values the knowledge of residents, giving them leadership, recognizing them as knowledge holders and enabling the sharing of this knowledge happens in these spaces. Here we present some actions developed by the Nova Hartz's History Museum (Nova Hartz / RS), which seeks this role, with special focus on intangible heritage of the municipality.

Keywords: museum, cultural heritage, Nova Hartz/RS 
Inicio este artigo com uma frase de Mario Chagas (s/d, p. 3), uma vez que ela indica a reflexão que desejamos desenvolver neste espaço. Escreve ele que "[...] museu e patrimônio constituem campos distintos e complementares, que frequentemente dançam ao som de uma mesma música. Ora é um, ora é o outro quem conduz a dança.”.

O Museu Histórico de Nova Hartz localiza-se, como o nome evidencia, no município de Nova Hartz/ RS, região metropolitana de Porto Alegre. Foi colonizado por imigrantes alemães e seus descendentes a partir do ano de 1847 , dentro do contexto da imigração alemã para o Rio Grande do Sul, ocorrida desde do ano de 1824. Trata-se de um pequeno museu local, em um município que possui atualmente 19.000 habitantes. Inaugurado em 03 de dezembro de 1999, o Museu impulsionou/fomentou no município as discussões referentes ao patrimônio cultural local, e hoje é pelo museu que passam todas as questões referentes a proteção, preservação, divulgação, pesquisa e valorização desse patrimônio.

Assim, verifica-se a relação entre esses fatores e a fala de Chagas supracitada, pois concebemos os museus a partir do contexto do patrimônio cultural, com relações imbricadas, com ações que se inter-relacionam e se complementam. O Museu, desta forma, torna-se parte do processo de construção do sentimento de pertença, de territorialidade, de identidade.

Chagas (s/d, p. 3) ainda declara que, antes que houvesse uma legislação relativa à proteção do patrimônio cultural no Brasil, já havia museus preocupandose com a prática da preservação - e no município de Nova Hartz essa premissa se manteve. Por trabalhar sempre de maneira concomitante as ações do Museu e as ações de preservação do patrimônio material e imaterial do município como um todo, é que se foi construindo de maneira muito natural um trabalho que engloba ambas. A participação da comunidade com suas memórias, seus saberes, seus referenciais culturais caminham junto com a construção dos saberes ditos científicos, com as pesquisas acadêmicas, com uma metodologia de trabalho mais tradicional, baseada em documentação escrita.

Nesse sentido, para que haja a participação efetiva da comunidade, é necessário que os museus mudem sua forma de pensar e atuar. É preciso que deixem de se ver como detentores únicos e indiscutíveis dos saberes, de modo que percebam a comunidade tanto como detentora de saberes, como também tendo condições de tornar inteligível o conhecimento sobre sua própria comunidade, para os moradores locais e visitantes. O Museu, então, pode ser entendido como um lugar de memória ${ }^{1}$, um lugar que se reveste de significados e, assim como o patrimônio,

para além de suas possiveis serventias políticas e científicas [...] são dispositivos narrativos, servem para contar histórias, para fazer a mediação entre diferentes tempos, pessoas e grupos. É neste sentido que se pode dizer que museus são pontes, janelas ou portas poéticas que servem para comunicar e, portanto, para nos humanizar (CHAGAS, s/d, p. 5).

Não obstante, para "humanizar", para criar pontes, busca-se uma prática museológica em que a participação da comunidade se faça presente, de maneira que suas memórias sejam valorizadas como referência para compreender e conhecer o patrimônio imaterial do município e da região de colonização alemã, na sua totalidade e complexidade. Assim, o patrimônio pode ser

\footnotetext{
${ }^{1}$ Aqui entendido na perspectiva de Pierre Norá (1993, p. 21) para quem são lugares “[...] nos três sentidos da palavra, material, simbólico e funcional, simultaneamente, somente em graus diversos. [...] só é lugar de memória se a imaginação o investe de uma aura simbólica [...]".
} 
espaço de "partilha da aprendizagem" (PINTO, 2013, p. 9), partilha de conhecimento entre os moradores idosos, especialmente - e os alunos, promovendo o encontro, a interação entre as gerações.

Nessa perspectiva, o Museu Histórico de Nova Hartz vem buscando, durante sua trajetória, abrir espaço para o protagonismo da comunidade, fazendo com que saberes sejam transmitidos em primeira pessoa, e com que a interpretação dos objetos e do patrimônio, material e imaterial, seja realizada por atores locais. Algumas das ações realizadas pelo Museu nesse sentido, e que pretendemos destacar neste artigo, são: exposição temporária da Páscoa: "A Páscoa no tempo dos avós"; exposição temporária do Natal: "Tannenbaum"; participação na Semana do Bebê; Projeto Cozinhando Memórias; Projeto de educação para o patrimônio: "Você é feito de histórias"; Projeto de História Oral.

A primeira ação que gostaríamos de registrar éo projeto de criação de um banco de dados de História de Oral, no qual o Museu registra as memórias dos moradores, de acordo com as pesquisas que estejam sendo realizadas. Essas entrevistas servem como base documental a ser apreciada e utilizada, valendo-nos da mesma criticidade e análisedispensada aos documentos escritos. Baseando-se nesses depoimentos, muitas exposições são organizadas ou enriquecidas, visto que os relatos e as vivências dos moradores dão vida, poesia e nos humanizam, como escrito por Chagas (s/d, p. 5).

As atividades realizadas no período da Páscoa, por meio da exposição temporária chamada "A Páscoa no tempo dos avós", são parte integrante de processo de interação entre a comunidade e o Museu. Essa exposição acontece desde2003 e, desde a sua primeira edição, foi organizada a partir das memórias de moradores. Antigos moradores contaram-nos como elaboravam seus ninhos de Páscoa, na sua infância: usando barba-de-pau, fazendo-os dentro de pratos, chapéus, bacias, peneiras ou diretamente em cima de bancos. Também nos informaram como os enfeitavam com flores e chás e o que ganhavam de presente de Páscoa. Os mais antigos, que hoje estariam com mais de 90 anos de idade, relataram-nos que ganhavam ovos cozidos coloridos nos seus ninhos de Páscoa, tradição esta que os imigrantes trouxeram consigo quando vieram da Alemanha e se estabeleceram na região. Outros moradores, da geração seguinte, lembram que ganhavam, além dos ovos cozidos, biscoitos decorados com merengue e com açúcar colorido, ovo de açúcar, casquinhas de ovos recheadas com um doce feito de açúcar e amendoim. Essas casquinhas eram pintadas com tintas extraídas de plantas, ou com papel crepom. Alguns ganhavam algumas balinhas e eventualmente uma pequena barra de chocolate. Até o ano de 2014, era a equipe do Museu que recebia as turmas de alunos que agendavam visitas à exposição e eram narradas a elas as memórias dos moradores. Ou seja, essas pessoas eram escutadas pela equipe do Museu para fazer a montagem da exposição e relatar suas memórias acerca da Páscoa, mas não tinham contato com as turmas de alunos que visitam a exposição. No ano de 2015, decidimos convidar esses moradores para relatar às crianças as suas histórias, as suas lembranças sobre a Páscoa na infância. A experiência foi extremamente produtiva e gratificante para os alunos, para os moradores e para a equipe do Museu. O patrimônio intangível trouxe, de fato, a possibilidade de entendimento sobre vários aspectos da cultura local que alguns alunos desconheciam, por serem portadores de outras tradições culturais, e outros porque em suas famílias não há o espaço para conversa entre as gerações. Nesse sentido, Pinto (2013, p. 2) escreve:

(...) o conceito de imaterial vem acrescentar ao patrimônio cultural e aos museus (...) sublinhar a importância do lado intangivel da cultura, os traços afetivos e espirituais, a sensibilidade, as tradições, os valores, as festas, os lugares, tudo o que não é tangível e que tem a sua 
apreensão através dos sentidos e tem a sua expressão fora do museu. Esta essência social que dá vida à existência imaterial faz dos individuos protagonistas indispensáveis do objeto patrimonial.

No momento em que pessoas idosas da comunidade têm a oportunidade de se sentar com crianças e jovens, especialmente, e falar-lhes de suas memórias sobre as tradições culturais presentes na comunidade, amplia-se a possibilidade de que essas tradições culturais não se percam. É na transmissão intergeracional ${ }^{2}$ que se mantém a possibilidade da manutenção das tradições, mesmo que de maneira atualizada, como acontece com os elementos culturais de uma maneira geral — ainda que seu significado seja somente de memória. Assim, os moradores que iam até o Museu e conversavam com as crianças sobre a Páscoa da sua infância sentiam-se valorizados e despertavam nos alunos e professores outra disposição com relação ao patrimônio imaterial. Quando se fala de si, fala-se com a alma, e deixam-se fortes impressões nos ouvintes.

Para marcar ainda mais essa experiência, a equipe do Museu recolhe cascas de ovos junto à comunidade, pinta com papel crepom, faz o cricri (doce de amendoim cozido com açúcar), recheia as casquinhas e presenteia cada visitante com uma delas, referenciando o presente que as crianças ganhavam na Páscoa antigamente. $\mathrm{O}$ resultado foi tão positivo que, neste ano de 2016, repetimos a experiência. A cada turma que marcava previamente sua visita, havia um morador para falar com eles, com idades entre 65 e 93 anos. Esses relatos são riquíssimos, reveladores dos modos de ser e de viver, de tradições religiosas, tradições alimentares, tradições familiares, até mesmo referenciando questões relacionadas ao comércio local, aos meios de transporte da época em questão e às relações de consumo.

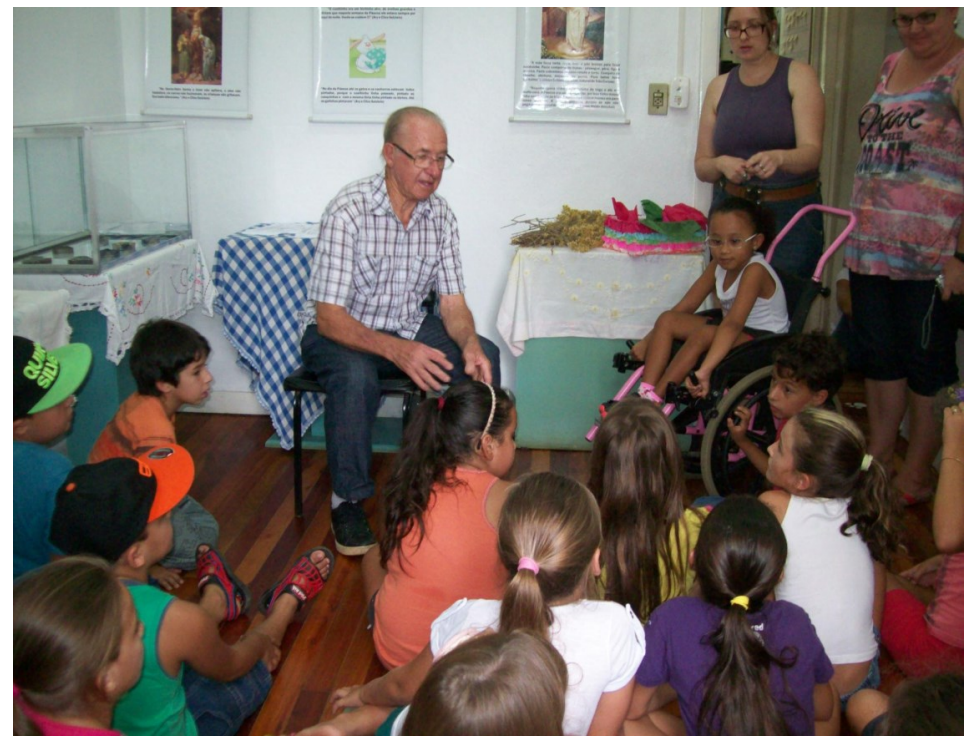

Imagens 1 e 2- Exposição "A Páscoa no tempo dos avós". Pictures 1 and 2- Exhibition "Easter at the grandparent's time".

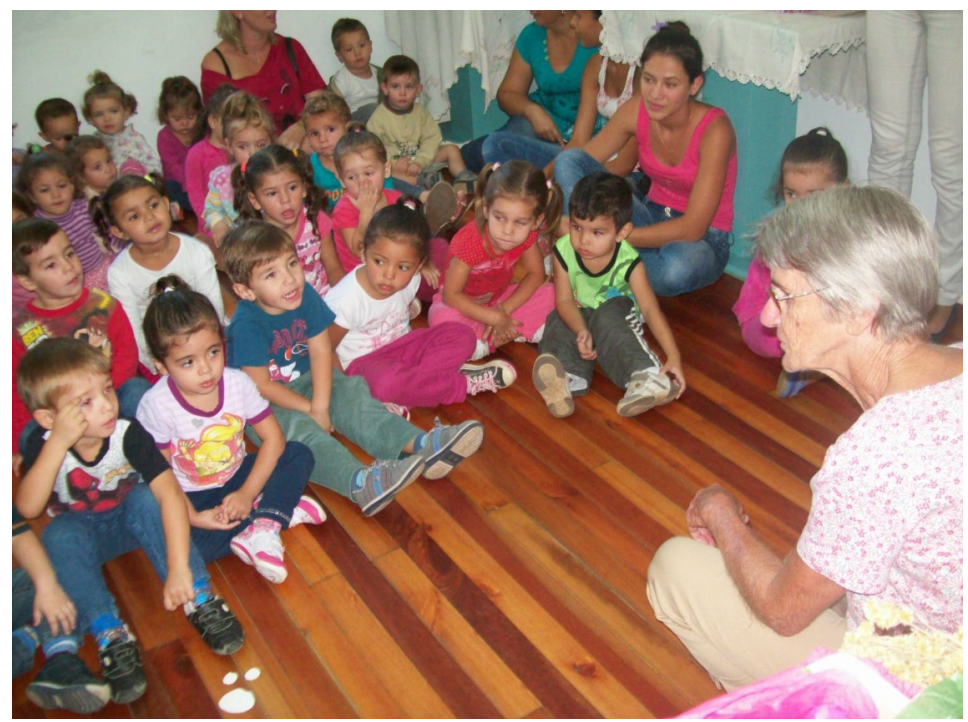

Imagem 2

Picture 2

Com a exposição do Natal chamada "Tannenbaum", que foi realizada pela primeira vez em 2005 e vem sendo realizada bianualmente, o envolvimento da comunidade está relacionado à montagem da exposição e ao relato das suas memórias sobre a data. A tradição do Pinheiro de Natal veio junto com imigrantes alemães. Assim, a forma como enfeitavam a árvore, o significado desses elementos decorativos, os doces que ganhavam, o envolvimento das crianças no preparo es-

\footnotetext{
${ }^{2}$ SPANHOL; LIMA FILHO; LIMA (2010, p. 33): "Entende-se como transmissão intergeracional a herança material e simbólica passada de geração a geração. Essa transmissão se dá por meio de construções simbólicas, transmitidas dos antecedentes aos descendentes".

${ }^{3}$ Palavra do dialeto Hunsrück, um dos dialetos trazidos da Alemanha pelos imigrantes e ainda falado por muitos moradores da região de colonização alemã, que significa, numa livre tradução "Pinheirinho de Natal"
} 
pecialmente das "bolachinhas pintadas" — biscoitos caseiros, decorados com merengue e açúcar colorido, chamadas pela comunidade apenas de "doce" - , a utilização de formas de folha de flandres (geralmente feitas com reaproveitamento de latas de azeite) para recortá-las, o costume de enviar e receber cartões de Natal, tudo isso é relatado pelos moradores e apresentado para as turmas de alunos e visitantes em geral nessa exposição. Nela, também o patrimônio imaterial representado pela gastronomia, pelas festas, pela religiosidade é marcado e mostrado pelo olhar dos moradores locais.

Duas experiências realizadas no ano de 2015 foram também muito significativas e envolveram a participação do Museu Histórico de Nova Hartz nas atividades da Semana do Bebê (mês de outubro) e da Feira do Livro (final de novembro) realizadas pela Secretaria Municipal de Educação, Cultura, Esporte e Lazer SMECEL, do Município de Nova Hartz. No primeiro evento, ao ser convidado para propor uma atividade e fazer parte da programação, o Museu promoveu um encontro de gerações, objetivando a troca e a valorização dos conhecimentos empíricos desse grupo. Assim, convidamos senhoras com idades entre 63 e 92 anos para virem conversar com mães mais jovens, falando desde como deveria se comportar uma mulher grávida, às soluções encontradas para resolver problemas como cólicas e dor de ouvido, e até mesmo o envolvimento masculino na educação das crianças. Foi um momento muito rico, de muita troca de experiências, com muitas perguntas, muitas descobertas e muito encantamento. Ao falar sobre sua experiência de maternidade, elas estavam falando de muitos outros elementos relacionados à época: os costumes, as superstições, as condições de saúde, os hábitos de higiene, o comércio local, a religiosidade, a sociabilidade, sobre o que era ser mulher nas décadas de 1930 a 1970 . Nessa linha, Santos (2000, p. 15) afirma que não vê "[...] outro caminho senão aquele que conduz à ação e à reflexão, porque [acredita] que a produção do conhecimento também pode ser resultado de um trabalho coletivo". Esses momentos de encontro e de troca entre gerações, efetivamente possibilitam construir conhecimento acerca de uma determinada época, de maneira leve e que valoriza os saberes dos indivíduos locais.

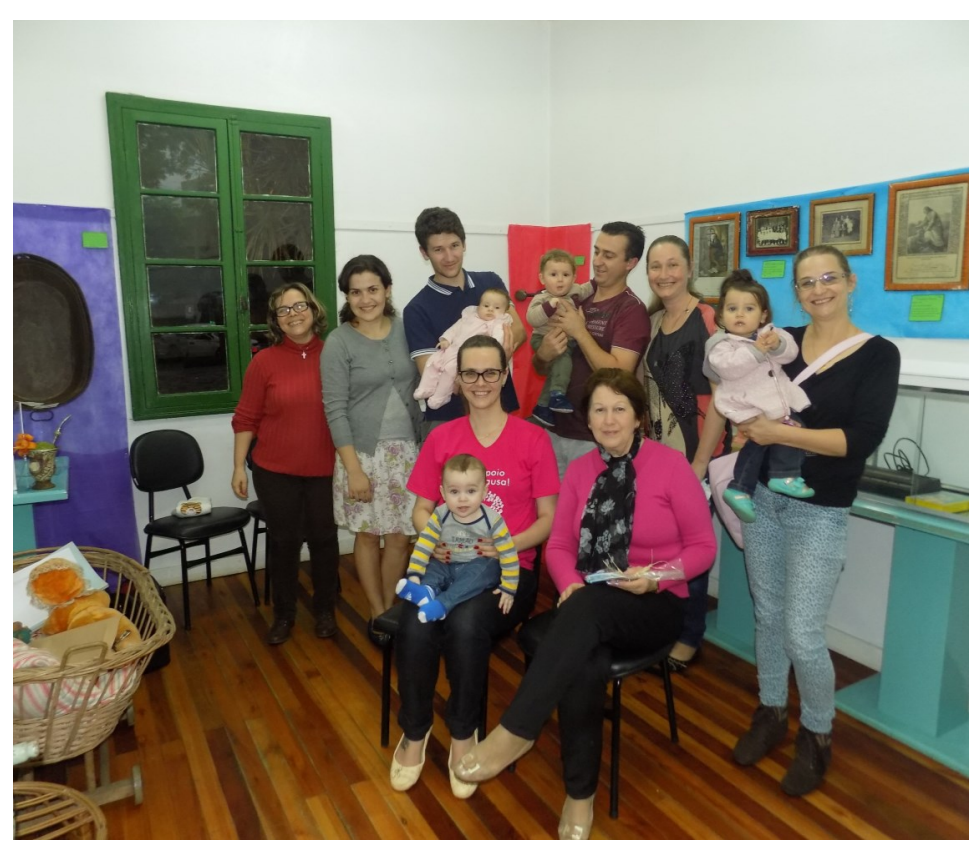

Imagens 3 e 4-Atividades da Semana do Bebê. Pictures 3 and 4-Activities of Baby's Week.

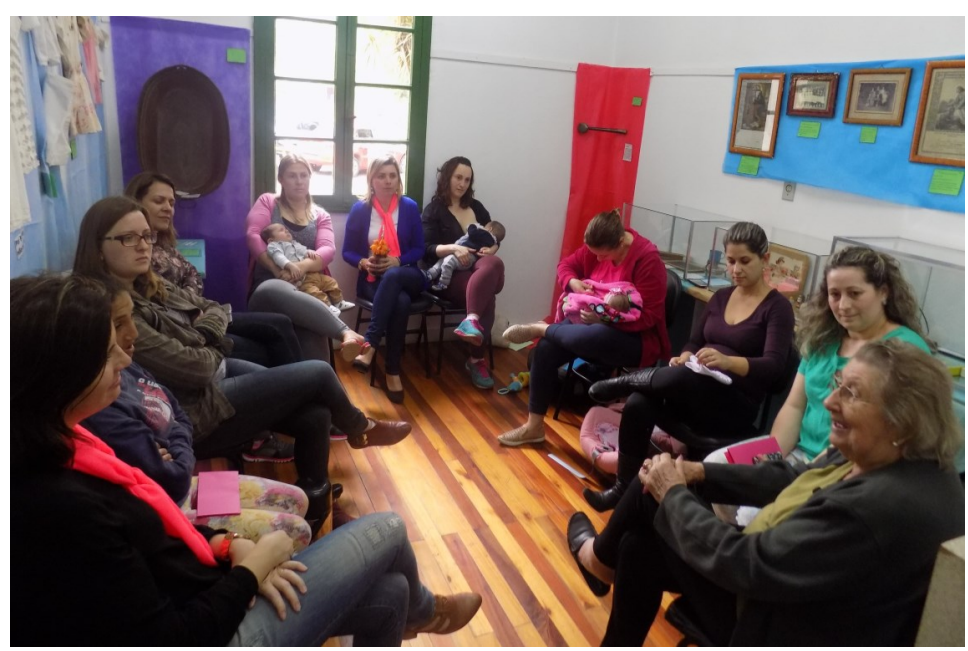

Imagem 4

Picture 4

Com a feira do livro, o processo foi mais longo, iniciando-se em agosto 2015 e sendo concluído na Feira do Livro 2015, em 26 de novembro. Esse projeto foi desenvolvido pelo Museu Histórico de Nova Hartz e 
pela Biblioteca Pública Municipal Guilherme Hartz, com pessoas da terceira idade, que participavam dos grupos de alongamento organizados pela Secretaria Municipal de Ação Social.

Os objetivos do projeto, chamado "Cozinhando Memórias", iam da formação de um público leitor à valorização e registro das memórias gastronômicas dos participantes. Os grupos foram visitados e o projeto apresentado, tendo tido a adesão de 11 mulheres. Os primeiros encontros foram de leitura e conversas: a diretora da Biblioteca, Jaqueline Fick, realizava a cada encontro a leitura de um ou dois capítulos do livro da patronesse da Feira do Livro, Rosane Rios, cujo título é "Pão feito em casa". Após a leitura, havia uma conversa sobre o que foi lido, nos dois primeiros encontros; nos demais, as participantes iam, espontaneamente, contando sobre alguns pratos que elas faziam e as memórias que estavam ligadas a eles. Fomos agendando visitas das participantes ao Museu, para fazer o registro das receitas escolhidas por cada uma delas e das memórias relacionadas a essas receitas. Posteriormente, foi feito um livro artesanal contendo as receitas e as memórias. Estas, em uma parceria com as escolas, foram apresentadas na forma de esquetes ${ }^{4}$ durante a programação da Feira do Livro, no dia 26 de novembro.

Após as apresentações abertas ao público, foi feito o lançamento do livro, e as participantes (algumas semialfabetizadas) autografaram os que foram vendidos. De fato, esse projeto foi especialmente emocionante. A alegria das mulheres autografando os livros extrapolou as nossas expectativas. A emoção e os agradecimentos feitos à equipe, por proporcionar um momento nunca imaginado por elas, compensaram as dificuldades encontradas no caminho, especialmente com relação à logística do projeto e às dificuldades de financiamento do livro.

Outrossim, foram vários outros pontos significativos: essas mulheres não se encaixam no perfil de público das Feiras de Livro em Nova Hartz. Se não fosse em função do projeto, nunca teriam ido visitar a Feira. A troca que aconteceu entre elas e os alunos foi igualmente importante, pois eles tiveram que compreender o contexto em que elas viviam para que fosse possível elaborar os esquetes. Além disso, a valorização e o registro das memórias gastronômicas de moradores, vindos de outros lugares ou sendo naturais de Nova Hartz, foram outro ponto relevante.

Desta forma, o patrimônio imaterial pôde ser conhecido, interpretado, significado, registrado, vivenciado, e o Museu permitiu que houvesse a interação entre ele e o meio em que está inserido. Baseando-nos em Pollak (1989, p. 3), que considera que ao privilegiar "[...] a análise dos excluídos, dos marginalizados e das minorias, a história oral ressaltou a importância de memórias subterrâneas que, como parte integrante das culturas minoritárias e dominadas [...]reabilita a periferia e a marginalidade", entendemos que as memórias de mulheres e a temática ligada à memória gastronômica passa a ser valorizada e estudada dentro da perspectiva da história cultural e da micro história e entendida como relevante para o estudo de determinado grupo social. O que o Museu promoveu, ao dar voz a essas minorias, é a dignidade e o protagonismo a grupos e temáticas antes excluídos das pesquisas.

\footnotetext{
${ }^{4}$ Pequenas cenas de teatro, de curta duração.
} 
Quando os alunos visitam propriedades de interesse histórico, de uma maneira geral são recebidos pelos próprios moradores ou por membros das igrejas, que contam a eles detalhes sobre o lugar e sobre o que foi vivido ali. É muito raro que um morador não deseje a visita das turmas de alunos e não os receba com carinho, embora aconteça em casos bem específicos, e com motivações também bem específicas. Além dos alunos e professores saberem quando a propriedade foi construída, quem morou ali, qual a técnica construtiva empregada, eles também ficam sabendo sobre os modos de ser e de viver, sobre as tradições culturais daquela família e sua ligação com os demais moradores. Do mesmo modo, entram em contato com as memórias afetivas que ligam o morador à casa e os demais membros da comunidade àqueles acontecimentos vividos ali, ou vividos por moradores daquele espaço. Dessa maneira, a preservação do patrimônio cultural passa a ganhar significado, uma vez que ela passa a ser entendida, significada e possibilita "[...] compreender e interpretar os objetos e analisar sua relação com o passado, com o presente e sobre aquilo que conseguem transmitir e construir, marcando um percurso dentro da atividade humana" (PINTO, 2013, p. 7).

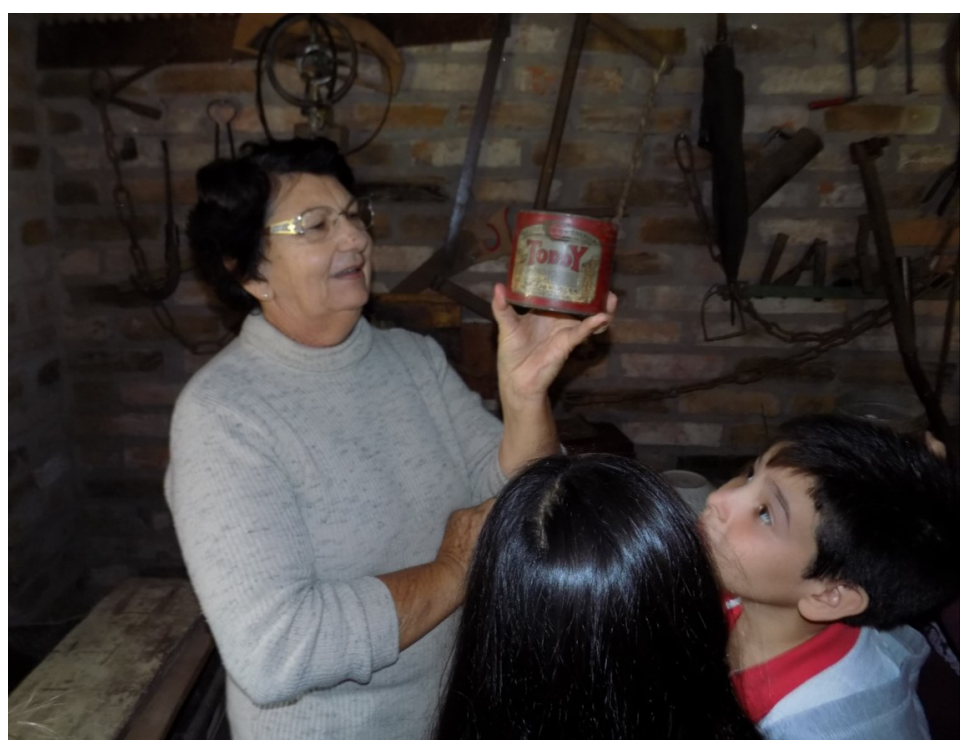

Imagens 7 e 8- Projeto de Educação para o Patrimônio "Você é Feito de Histórias".

Pictures 7 and 8 -Education project for the Heritage "You're Made of Stories".

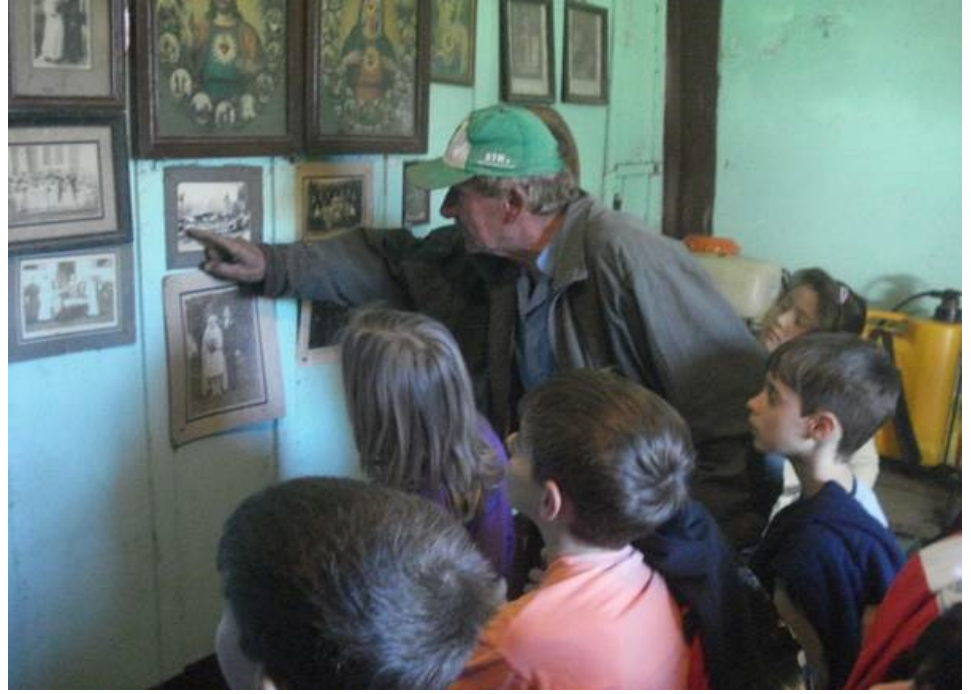

Imagem 8

Picture 8

Fica claro, para nós, que essas exposições e ações que trabalham com o cotidiano da comunidade $\mathrm{e}$ com a participação dela, humanizando os espaços, isto é, mostrando-os na sua totalidade como espaço de história e de memória, permitem que o passado e o presente se cruzem.Oportunizam, consequentemente, a apropriação dos espaços, a compreensão das memórias e tradições culturais como forma de respeitar e proteger. Desta forma, a proteção deixa de ser vista de forma burocrática pelos grupos envolvidos, e a criação de laços afetivos da comunidade com esses espaços acontece de uma forma mais efetiva e profunda.

Ancorados em Norbert Elias (1994, p. 26-27), entendemos que, quando as tradições culturais deixam de ter significado, elas irão "morrer". Porém, quando apenas“" $[. .$.$] adormecem [...] [e] adquirem um novo val-$ or existencial [...]",poderão voltar a ser relembrados e a fazer parte do cotidiano do grupo. Por conseguinte, as palavras-chave para que as tradições se mantenham são significado e transmissão. Portanto, o envolvimento e o protagonismo da comunidade nas ações desenvolvidas pelo museu dão significado ao patrimônio tangível e intangível, bem como proporcionam que a transmissão aconteça. 
Como não existe um único modelo e uma receita a ser seguida na atuação em museus, o Museu Histórico de Nova Hartz se propõe a realizar ações que, em nosso entendimento, busquem a interação com e entre a comunidade, tornando-se uma prática o menos esporádica possível, buscando cada vez mais interligar a co- munidade, em sua prática cotidiana, e entendendo que, com isso, o museu “[...] não perde competência científica [...]" (PINTO, 2013, p. 9), mas ganha em conhecimento, comunicação e construção de interpretação do patrimônio. Efetivamente, essas ações aproximam o Museu da comunidade e a comunidade do Museu.

\section{Referências bibliográficas}

CHAGAS, Mario. Educação, Museu e Patrimônio: tensão, devoração e adjetivação. s.d. Disponível em: <http:// portal.iphan.gov.br/uploads/ckfinder/arquivos/ educacao_museu_patrimonio_tensao.pdf $>$. Acesso em: 3 maio 2016.

ELIAS, Norbert. O processo civilizador. Uma história dos costumes. Rio de Janeiro: Jorge Zahar Ed., 1994.

NORÁ, Pierre. Entre a memória e a história: a problemática dos lugares. Projeto História. São Paulo, n. 10, dez. 1993.

PINTO, Celina Bárbaro. Museu, comunidade e património cultural imaterial: um estudo de caso - o Museu da Terra de Miranda. 2013. Disponível em: $<$ https://midas.revues.org /210\# bodyftn4 $\geq$ Acesso em: 3 maio 2016

POLLAK, Michael. Memória, Esquecimento, Silêncio.1989.Disponível em: $<$ http:// www.uel.br/cch/cdph/arqtxt/ Memoriaesquecimentosilencio.pdf> Acesso em: 13 fev. 2012.

SANTOS, Maria Célia T. Moura.Museu e comunidade: uma relação necessária. 2000. Disponível em: <http:// www.abremc.com.br/pdf/13.pdf> Acesso em: 5 maio 2016.

SPANHOL, Caroline Pauletto; LIMA FILHO, Dario de Oliveira; LIMA, Maria de FátimaEvangelista Mendonça. Transmissão intergeracional: uma contribuição ao estudo do comportamento do consumidor de alimentos. Revista Contemporânea de Economia e Gestão, v. 8, n. 2, jul./dez. 2010, p. 31-40. Disponível em: <http:// www.contextus.ufc.br/ index.php/ contextus/article/view/265/94> Acesso em: 25 fev. 2013.

Submissão: $22 / 05 / 2016$

Aceite: $25 / 10 / 2016$ 